\title{
Analysis on the Synergy Evolutionary Development of the Collecting, Distributing, and Transporting System of Railway Heavy Haul Transportation
}

\author{
Fenling Feng, Dan Lan, and Liuwen Yang \\ School of Traffic and Transportation Engineering, Central South University, Changsha 410075, China
}

Correspondence should be addressed to Fenling Feng, ffl0731@163.com

Received 2 October 2012; Accepted 12 October 2012

Academic Editor: Wuhong Wang

Copyright (c) 2012 Fenling Feng et al. This is an open access article distributed under the Creative Commons Attribution License, which permits unrestricted use, distribution, and reproduction in any medium, provided the original work is properly cited.

A synergy evolutionary model of the collecting, distributing, and transporting system of railway heavy haul transportation is built by introducing synergy-related concepts and applying synergy evolutionary theory. Then spline interpolation method, numerical differential five-point formula, and method of least squares are used to solve synergistic coefficient, while fourth-order Ruggekutta method and fourth-order Adams linear implicit formula method are used to solve coevolutionary curve of the system. Finally, the heavy load transportation of Daqin Railway is an example of the empirical analysis. The research result shows that the degree of order of the system and its three subsystems-collecting, transporting, and distributing-increases as the synergetic coefficient of the subsystems increases; otherwise, the degree of the order will decrease. It also shows that this model can better analyze the coevolutionary process of the heavy load collecting, distributing, and transporting system of Daqin Railway, with its rationality and applicability verified.

\section{Introduction}

The collecting, distributing, and transporting system has served as a platform or bond to connect multiple means of transportation. It is critical to organize integrated transportation whose rapid and efficient implement requires orderly synergy between its three subsystems—collecting, transporting, and distributing. Studying the coevolutionary development of collecting, distributing, and transporting system helps to detect weaknesses and take corresponding measures to improve the orderly synergy of the entire system; it also helps to reveal laws concerning its evolution, making it more orderly and efficient.

Theory research of the coevolutionary development has hardly been done from the system point of view. Collaborative development in the field of transportation is mostly 
about the synergy between the various modes of transportation. Studies are mainly focused on the measures of collaborative development, while few studies have been done to reveal the evolution law. Hook and Replogle [1], by taking the example of China, Japan and India, studied the street space to configure and use from the aspect of motorization influencing public policy. Adler et al. [2] explored the use of cooperative, distributed multiagent system to improve dynamic routing and traffic management. Hackney and Marchal [3] considered the influence of traveler transportation options which have optional range, mode and orientation preference, coordination degree, and alternative tools and can mobilize resources and other factors, using the simulation tool, the study of travelers' self-organization of transferring routing behaviors. Jeong et al. [4] discussed service chain which exists in relatively centralized flow, and the radial network hub has been widely applied in European freight railroad system, which provided reference to China's bulk cargo fast collection and distribution network. Konings [5] studied the integrated center with multimodal transport, storage, integrated with cargo transport and distribution, and offering good reference for railway transportation system. Fenling and Dan [6] constructed a cellular automata model for Daqin Railway in China by combining the rail transit system and cellular automata mode based on the four-aspect fixed block system, and Fenling and Feiran [7] set the incentive goal for cargo distribution and transportation system and further built an incentive model for the cargo distribution and transportation system that involves one principal and multiple agents. Jun et al. [8] used the data envelopment analysis model to evaluate the synergetic development of city tease based on the input-output matrix and the index of sustainable development, providing an approach of evaluating the validity degree of "synergic" and "development" within the city traffic system and among subsystems. Yan and Bei-Hua [9] analyzed the structure and synergetic character of MMTS with systematic science method and constructs the synergy equation for MMTS.

The coevolutionary development of collecting, distributing, and transporting subsystems has mainly been strengthened in practice by taking certain measures. Huaihai [10] used a three-dimensional modeling technology to analyze the system static structure, control element, and function simulation of the collecting and distributing system. Considering the system demand and the function of coupling system, he proposed a coupling system functional structure optimization method. Then he summarized transfer modes and spatial distribution modes among collecting and distributing subsystems in the passenger transport hub.

The coevolution has been widely used in the resource, environment, economic, and ecological systems. Norgaard [11] described the relationship between the economy and the environment. Coevolution theory is the combination of ecology and complex scientific synergy. Coevolution is not only the "synergy," but also the "evolution." It is the evolution relationship of various mutual influenced factors. Costanza et al. [12] argued that the system dynamics for the study of natural and man-made system relationship has important sense, and a broad interdisciplinary system concept has been applied to a series of technology. Holling [13] studied economic, environmental, and social relations. Aihua et al. [14] analyzed the interaction among subsystems and factors of water resources, social economy, and ecoenvironment and studied the evolving mechanism, mode, order parameter, controlling parameter, and synergetic frame of the water resources-social economy-eco environment. Yuming and Yan [15] analyzed the space-time distribution of the coordination degrees in China's 31 provinces in 1995, 2000, and 2005 empirically based on 18 indicators of economic subsystem and environmental subsystem and through employing models of coordination degrees of economic growth and environment and method of weighted entropy value. 
Shangyou et al. [16] expounded the water resources ecological economic complex system, which is the objective reality of the practical and theoretical evolutionary processes of water resources planning and management based on positive methodology and system theoretical analysis. Xiangdong et al. [17] used the synergetics theory as a foundation to establish the multiplexed system's degree of order models and the multiplexed system's coordination evolution model through the system analysis of water resources restraint. Qingsong and Wenxiu [18] constructed a kind of practical calculation of composite system coordination degree model based on synergetics. Bak and Chen [19] described the concept of selforganization and its characteristic. Bobrek and Sokovic [20] discussed the management of modern enterprises for the implementation of total quality management and the synergistic effect of the general system theory.

This paper will mainly discuss degree of order, using synergy evolutionary theory to analyze the developing process of coevolution of the collecting, distributing, and transporting system and reveal the synergy evolutionary laws between all subsystems and laws of the entire system.

\section{Synergy Evolutionary Model of the Collecting, Distributing, and Transporting System of Railway Heavy Haul Transportation}

Synergy evolutionary model of the collecting, distributing, and transporting system of heavy haul transportation mainly builds its synergetic development model on the basis of the degree of order of its three subsystems.

\subsection{Analysis on the Degree of Order of the Collecting, Distributing, and Transporting System of Railway Heavy Haul Transportation}

Synergetics holds that synergy refers to the mutual coordination and synchronization between components in the developing process of the system, the degree of which is also called degree of order, and the synergetic effect determines the evolutionary trends and approaches of the system when it moves from disorder to order.

Assume that $n_{i}(t)(i=1,2,3)$ refers to the degree of order of collecting subsystem, transporting subsystem, and distributing subsystem at the time of $t$, respectively, and all the parameters in the developing process of the subsystems are $x_{i}=\left(x_{i 1}, x_{i 2}, \ldots, x_{i m}\right)$, where $m \geq 1, \beta_{i j} \leq x_{i j} \leq \alpha_{i j}, j \in[1, m]$. Here, $\alpha_{i j}, \beta_{i j}$ refer to the upper bound and lower bound of parameter $x_{i j}$ obtained from the stability critical point of the system. Without loss of generality, assume the greater the value of $x_{i s+1}, x_{i s+2}, \ldots, x_{i m}$, the lower the degree of order of the subsystems $n_{i}$, otherwise the higher the degree of order of the subsystems, $n_{i}$. A common method used to solve the degree of order of subsystem parameters is

$$
n_{i}\left(x_{i j}\right)=\left\{\begin{array}{ll}
\frac{x_{i j}-\beta_{i j}}{\alpha_{i j}-\beta_{i j}} & j \in[1, s] \\
\frac{\alpha_{i j}-x_{i j}}{\alpha_{i j}-\beta_{i j}} & j \in[s+1, m]
\end{array} \quad i=1,2,3,\right.
$$

where both the maximum value and minimum value of the parameters are transformed into 1 and 0 , or 0 and 1 in the solution process when some parameters have wide range of variation 
and some narrow range of variation. In such case, the relative role of parameters with narrow range of variation is exaggerated in the calculation of synergetic degree. Therefore, this paper adopts the following formula to solve the parameter's degree of order:

$$
n_{i}\left(x_{i j}\right)=\left\{\begin{array}{ll}
\frac{x_{i j}}{2 \alpha_{i j}-\beta_{i j}} & j \in[1, s] \\
1-\frac{x_{i j}}{2 \alpha_{i j}-\beta_{i j}} & j \in[s+1, m]
\end{array} \quad i=1,2,3 .\right.
$$

From formula (2.2) we know that $n_{i}\left(x_{i j}\right) \in[0,1]$, which is the degree of order of parameter $x_{i}$. The total contribution of parameter $x_{i}$ to the degree of order of the subsystems can be realized through the integration of $n_{i}\left(x_{i j}\right)$. The overall performance of subsystems depends not only on the numerical value of all parameters but also on their combining forms, for the forms directly determine the law of "integration." In practice, we often use geometric average method and linear weighted summation method to solve the degree of order of the subsystems. Thus we can obtain $n_{i}$ :

$$
n_{i}=\sqrt[m]{\prod_{j=1}^{m} n_{i}\left(x_{i j}\right)} \quad \text { or } \quad n_{j}=\sum_{j=1}^{m} \omega_{j} n_{i}\left(x_{i j}\right) \sum_{j=1}^{m} \omega_{j}=1
$$

where $\lambda_{j}$ is the weight of the $j$ th component of parameter $x_{i}$. From formula (2.3) we know that the degree of order $n_{i} \in[0,1]$.

\subsection{Synergy Evolutionary Model of the Collecting, Distributing, and Transporting System of Railway Heavy Haul Transportation}

In order to show the mutual synergetic effect between all the subsystems, synergistic coefficient $\sigma_{i d}(i \neq d, i, d=1,2,3)$ is introduced to represent the synergetic effect imposed by subsystem $i$ on the degree of order of subsystem $d$. That is to say, the increase in the degree of order of subsystem $i$ will push a lift in the degree of order of subsystem $d$, with $0<\sigma_{i d} \leq 1$; parameter $\xi_{i}$ represents the combined effect imposed by the other two subsystems on subsystem $i$. In another word, it refers to the lift in the degree of order of subsystem $i$ brought about by the increase in the orderly synergetic degree of the other two subsystems, with $0<\xi_{i} \leq 1$. Thus we can obtain the synergy evolutionary equation of each subsystem:

$$
\begin{aligned}
& \frac{d n_{1}}{d t}=n_{1}\left(\delta_{1}-\lambda_{1} n_{1}+\sigma_{21} n_{2}+\sigma_{31} n_{3}+\xi_{1} \frac{\min \left(n_{2}, n_{3}\right)}{\max \left(n_{2}, n_{3}\right)}\right), \\
& \frac{d n_{2}}{d t}=n_{2}\left(\delta_{2}-\lambda_{2} n_{2}+\sigma_{12} n_{1}+\sigma_{32} n_{3}+\xi_{2} \frac{\min \left(n_{1}, n_{3}\right)}{\max \left(n_{1}, n_{3}\right)}\right), \\
& \frac{d n_{3}}{d t}=n_{3}\left(\delta_{3}-\lambda_{3} n_{3}+\sigma_{13} n_{1}+\sigma_{23} n_{2}+\xi_{3} \frac{\min \left(n_{1}, n_{2}\right)}{\max \left(n_{1}, n_{2}\right)}\right),
\end{aligned}
$$

where $\delta_{i}(i=1,2,3)$ is freely development coefficient (free from the influence of other subsystems and constrained by factors like its own environment), which represents 
the development degree of degree of order of the three subsystems in the condition that they are free from the influence of other subsystems and only constrained by factors like its own environment, with $0<\delta_{i} \leq 1$. With increase in the degree of order of the subsystems and restriction imposed by external resources, it will be more difficult for it to lift. Therefore, parameter $\lambda_{i}$ refers to retardation in the degree of order inflicted by the subsystems themselves, with $0<\lambda_{i} \leq 1 ; \min \left(n_{i}, n_{j}\right) / \max \left(n_{i}, n_{j}\right)$ refers to the synergetic degree between two subsystems.

The degree of order of the collecting, distributing, and transporting system of heavy haul transportation will be affected by that of its three subsystems. Set that the degree of order of all subsystem parameters is $n_{i}^{k-1}, i=1,2,3$ at a given time $t_{k-1}$. In terms of time $t_{k}$ which is in the developing and evolving process of the entire system, if the degree of order of all subsystem parameters is $n_{i}^{k-1}, i=1,2,3$, the synergy evolutionary equation of synergetic degree of the system, $N$, will be

$$
\frac{d N}{d t}=\theta \sqrt[3]{\left|\prod_{i=1}^{3}\left[n_{i}^{k}-n_{i}^{k-1}\right]\right|}
$$

where

$$
\theta=\frac{\min _{i}\left[n_{i}^{k}-n_{i}^{k-1}\right]}{\left|\min _{i}\left[n_{i}^{k}-n_{i}^{k-1}\right]\right|+\varepsilon} \quad\left(\varepsilon \longrightarrow 0^{+}\right), i=1,2,3
$$

where $\min _{i}\left[n_{i}^{k}-n_{i}^{k-1}\right]$ may be 0 . Therefore, an infinitesimal, $\varepsilon$, which is greater than 0 , is added to denominator to make it unequal to 0 . The role of parameter $\theta$ is to make sure that synergetic degree of the system will be positive if and only if $n_{i}^{k}-n_{i}^{k-1}>0$, for all $i \in[1,3]$.

According to the analysis above, the synergy evolutionary model of the collecting, distributing, and transporting system of heavy haul transportation can be,

$$
\begin{aligned}
& n_{i}\left(x_{i j}\right)=\left\{\begin{array}{l}
\frac{x_{i j}}{2 \alpha_{i j}-\beta_{i j}}, \quad j \in[1, s] \\
1-\frac{x_{i j}}{2 \alpha_{i j}-\beta_{i j}}, j \in[s+1, m]
\end{array} \quad i=1,2,3,\right. \\
& n_{i}=\sum_{j=1}^{m} \omega_{j} n_{i}\left(x_{i j}\right), \quad \omega_{j} \geq 0, \quad \sum_{j=1}^{m} \omega_{j}=1, \quad i=1,2,3, \\
& \frac{d n_{1}}{n_{1} d t}=\delta_{1}-\lambda_{1} n_{1}+\sigma_{21} n_{2}+\sigma_{31} n_{3}+\xi \frac{\min \left(n_{2}, n_{3}\right)}{\max \left(n_{2}, n_{3}\right)} \\
& \frac{d n_{2}}{n_{2} d t}=\delta_{2}-\lambda_{2} n_{2}+\sigma_{12} n_{1}+\sigma_{32} n_{3}+\xi_{2} \frac{\min \left(n_{1}, n_{3}\right)}{\max \left(n_{1}, n_{3}\right)},
\end{aligned}
$$




$$
\begin{gathered}
\frac{d n_{3}}{n_{3} d t}=\delta_{3}-\lambda_{3} n_{3}+\sigma_{13} n_{1}+\sigma_{23} n_{2}+\xi \frac{\min \left(n_{1}, n_{2}\right)}{\max \left(n_{1}, n_{2}\right)} \\
0<\sigma_{i d} \leq 1,0<\xi_{i} \leq 1, i, d=1,2,3, i \neq d, 0<\delta_{i} \leq 1,0<\lambda_{i} \leq 1, \\
\frac{d N}{d t}=\theta \sqrt[3]{\left|\prod_{i=1}^{3}\left[n_{i}^{k}-n_{i}^{k-1}\right]\right|} \\
\theta=\frac{\min _{i}\left[n_{i}^{k}-n_{i}^{k-1}\right]}{\left|\min _{i}\left[n_{i}^{k}-n_{i}^{k-1}\right]\right|+\varepsilon}, \quad i=1,2,3, \varepsilon \longrightarrow 0^{+} .
\end{gathered}
$$

\section{Solution to the Synergy Evolutionary Model of Collecting, Distributing, and Transporting System of Railway Heavy Haul Transportation}

\subsection{Determining the Weight of Each Subsystem Parameter $\omega_{j}^{i}$}

In the evolving and developing process of the railway freight system, the influence imposed by different parameters on the system is different. So we need to determine the weights of all parameters.

\section{(1) Standardization}

Since the measurement unit of each parameter is different, it will lead to great difference in the measured value of each parameter. So standardization of the original data should be carried out in the first place to make all parameters dimensionless.

Assume that $y_{t j}^{i}$ refers to the data of the $j$ th parameter in the $i$ th subsystem in the $t$ th year $(i=1,2,3, t=1,2, \ldots, k, j=1,2, \ldots, m)$. Set $\bar{y}_{j}^{i}$ to be the sample average of the $j$ th parameter in the $i$ th subsystem, then

$$
\bar{y}_{j}^{i}=\frac{1}{k} \sum_{t=1}^{k} y_{t j}^{i}
$$

Set $R_{j}^{i}$ to be the sample variance of the $j$ th parameter in the $i$ th subsystem, then

$$
S_{j}^{i}=\left[\frac{1}{k-1} \sum_{t=1}^{k}\left(y_{t j}^{i}-\bar{y}_{j}^{i}\right)^{2}\right]^{1 / 2},
$$

thus the standardized data is

$$
Y_{t j}^{i}=\frac{y_{t j}^{i}-\bar{y}_{j}^{i}}{S_{j}^{i}} .
$$




\section{(2) Determining the Correlation of Coefficient between All Parameters}

Correlation of coefficient reflects the degree to which all parameters affect each other. The greater the absolute value of the correlation of coefficient, the higher the degree that indicators affect each other, otherwise the lower the degree that indicators affect each other. The higher the total degree of correlation between a parameter and others, the greater the influence it imposes on other parameters. So we should give it a relatively great weight; otherwise, a relatively small weight will be given. Set $r_{k_{1} k_{2}}^{i}$ to be the correlation of coefficient between the $k_{1}$ th and $k_{2}$ th parameters in the $i$ th subsystem, and then the coefficient matrix of each parameter in the $i$ th subsystem is $R^{i}$

$$
R^{i}=\left|\begin{array}{cccc}
r_{11}^{i} & r_{12}^{i} & \ldots & r_{1 m}^{i} \\
r_{21}^{i} & r_{12}^{i} & \ldots & r_{2 m}^{i} \\
\ldots & \ldots & \ldots & \ldots \\
r_{m 1}^{i} & r_{m 2}^{i} & \ldots & r_{m m}^{i}
\end{array}\right|
$$

where

$$
r_{k_{1} k_{2}}^{i}=\frac{\sum_{j=1}^{m}\left(Y_{j k_{1}}^{i}-\bar{Y}_{j k_{1}}^{i}\right)\left(Y_{j k_{2}}^{i}-\bar{Y}_{j k_{2}}^{i}\right)}{\sqrt{\sum_{j=1}^{m}\left(Y_{j k_{1}}^{i}-\bar{Y}_{j k_{1}}^{i}\right)^{2}} \sqrt{\sum_{j=1}^{m}\left(Y_{j k_{2}}^{i}-\bar{Y}_{j k_{2}}^{i}\right)^{2}}}=\frac{\sum_{j=1}^{m} Y_{j k_{1}}^{i} Y_{j k_{2}}^{i}}{\sqrt{\sum_{j=1}^{m}\left(Y_{j k_{1}}^{i}\right)^{2}} \sqrt{\sum_{j=1}^{m}\left(Y_{j k_{2}}^{i}\right)^{2}}}
$$

when $k_{1}=k_{2}, r_{k_{1} k_{2}}^{i}=1$.

\section{(3) Determining the Weight of Parameters}

Set

$$
W_{k_{2}}^{i}=\sum_{k_{1}=1}^{m}\left|r_{k_{1} k_{2}}^{i}\right|-1
$$

then $W_{k_{2}}^{i}$ refers to the total degree of influence imposed by the $k_{2}$ th parameter in the $i$ th subsystem on the rest parameters. Those rest parameters are $m-1$ in total. If $W_{k_{2}}^{i}$ is relatively great, it indicates that the degree of influence imposed by the $k_{2}$ th parameter in the $i$ th subsystem on the rest parameters is relatively great and we should give it a relatively great weight; otherwise, a relatively small weight will be given. Therefore, we can obtain the weight of parameter $k_{2}$ by normalizing $W_{k_{2}}^{i}$ :

$$
\omega_{k_{2}}^{i}=\frac{W_{k_{2}}^{i}}{\sum_{k_{2}=1}^{m} W_{k_{2}}^{i}} .
$$




\subsection{Determining Natural Growth Rate $\delta_{i}$}

The common method used to solve natural growth rate is first, solve the growth rate over the previous years and then use average growth rate to approximate the natural growth rate. But in the case that historical data are relative few, this method will fail to reflect the growth trends in a desirable way. Since the integration of collecting, distributing, and transporting system of heavy haul transportation in our country has started relatively late, our historical data are relatively few and the average growth rate of degree of order falls short to reflect its developing trends in a desirable way. Thus, this paper improves the average growth rate method and adopts the five-point numerical differential formula to solve the natural growth rate. First, we should deal with the original data by dividing a year's time into ten equal parts and using cubic spline interpolation (short for spline interpolation) to expand the data. Take the time step as $h=0.1$ year. Assume that the value at the initial point is $x_{0}$, then the value of the $l$ th point, $x_{l}$, can be expressed as

$$
x_{l}=x_{0}+l h
$$

Next, we should use the numerical differential five-point formula to calculate the derivative of every point (including the original point and differentiation point). Thus we can obtain the general derivative formula of every point:

$$
\begin{gathered}
f^{\prime}\left(x_{0}\right)=\frac{-25 f\left(x_{0}\right)+48 f\left(x_{1}\right)-36 f\left(x_{2}\right)+16 f\left(x_{3}\right)-3 f\left(x_{4}\right)}{12 h}, \\
f^{\prime}\left(x_{1}\right)=\frac{-3 f\left(x_{0}\right)-10 f\left(x_{1}\right)+18 f\left(x_{2}\right)-6 f\left(x_{3}\right)+f\left(x_{4}\right)}{12 h}, \\
f^{\prime}\left(x_{l}\right)=\frac{f\left(x_{l-2}\right)-8 f\left(x_{l-1}\right)+8 f\left(x_{l+1}\right)-f\left(x_{l+2}\right)}{12 h}, \quad l=3,4, \ldots, n-2, \\
f^{\prime}\left(x_{p-1}\right)=\frac{-f\left(x_{p-4}\right)+6 f\left(x_{p-3}\right)-18 f\left(x_{p-2}\right)+10 f\left(x_{p-1}\right)+3 f\left(x_{p}\right)}{12 h}, \\
f^{\prime}\left(x_{p}\right)=\frac{3 f\left(x_{p-4}\right)-16 f\left(x_{p-3}\right)+36 f\left(x_{p-2}\right)-48 f\left(x_{p-1}\right)+25 f\left(x_{p}\right)}{12 h} .
\end{gathered}
$$

$f\left(x_{l}\right)$ refers to the cubic spline interpolation of $x_{i}, f^{\prime}\left(x_{l}\right)$ the derivative of $x_{l}$, and $p$ the number of points after data expansion. The precision of numerical differential five-point formula is $O\left(h^{5}\right)$, so in the collecting, distributing, and transporting subsystem we can obtain

$$
\frac{d n_{i l}}{n_{i l} d t}=\frac{d n_{i l} / d t}{n_{i l}}=\frac{f^{\prime}\left(n_{i l}\right)}{n_{i l}}, \quad i=1,2,3
$$

where $n_{1 l}, n_{2 l}, n_{3 l}$ are the points of degree of order over the previous years in the collecting, transporting and distributing subsystems obtained after using cubic spine interpolation, and formula (3.10) is used to calculate the growth rate of every point to solve the average growth rate and the natural growth rate of the three subsystems. 


\subsection{Solutions of the Self-Retardation Coefficients $\lambda_{i}$ of Each Subsystem and the Synergistic Coefficients $\sigma_{i d}$ between These Subsystems}

From formula (2.4) and formula (3.10), it comes to the following result:

$$
\begin{aligned}
& \frac{f^{\prime}\left(n_{1 l}\right)}{n_{1 l}}=\delta_{1}-\lambda_{1} n_{1 l}+\sigma_{21} n_{2 l}+\sigma_{31} n_{3 l}+\xi_{1} \frac{\min \left(n_{2 l}, n_{3 l}\right)}{\max \left(n_{2 l}, n_{3 l}\right)} \\
& \frac{f^{\prime}\left(n_{2 l}\right)}{n_{2 l}}=\delta_{2}-\lambda_{2} n_{2 l}+\sigma_{12} n_{1 l}+\sigma_{32} n_{3 l}+\xi_{2} \frac{\min \left(n_{1 l}, n_{3 l}\right)}{\max \left(n_{1 l}, n_{3 l}\right)} \\
& \frac{f^{\prime}\left(n_{3 l}\right)}{n_{3 l}}=\delta_{3}-\lambda_{3} n_{3 l}+\sigma_{13} n_{1 l}+\sigma_{23} n_{2 l}+\xi_{3} \frac{\min \left(n_{1 l}, n_{2 l}\right)}{\max \left(n_{1 l}, n_{2 l}\right)} .
\end{aligned}
$$

The left end of formula (3.11) is determined by formula (3.9). To solve the result, this paper applies the Method of Least Squares, which works out the parameter by finding the sum of squared errors between the minimized desired data and the real data. Therefore, formula (3.11) should firstly be transformed into the following formula:

$$
\begin{aligned}
& S_{1}=\sum_{l=0}^{p}\left[\frac{f^{\prime}\left(n_{1 l}\right)}{n_{1 l}}-\left(\delta_{1}-\lambda_{1} n_{1 l}+\sigma_{21} n_{2 l}+\sigma_{31} n_{3 l}+\xi_{1} \frac{\min \left(n_{2 l}, n_{3 l}\right)}{\max \left(n_{2 l}, n_{3 l}\right)}\right)\right]^{2}, \\
& S_{2}=\sum_{l=0}^{p}\left[\frac{f^{\prime}\left(n_{2 l}\right)}{n_{2 l}}-\left(\delta_{2}-\lambda_{2} n_{2 l}+\sigma_{12} n_{1 l}+\sigma_{32} n_{3 l}+\xi_{2} \frac{\min \left(n_{1 l}, n_{3 l}\right)}{\max \left(n_{1 l}, n_{3 l}\right)}\right)\right]^{2}, \\
& S_{3}=\sum_{i=0}^{p}\left[\frac{f^{\prime}\left(n_{3 l}\right)}{n_{3 l}}-\left(\delta_{3}-\lambda_{3} n_{3 l}+\sigma_{13} n_{1 l}+\sigma_{23} n_{2 l}+\xi_{3} \frac{\min \left(n_{1 l}, n_{2 l}\right)}{\max \left(n_{1 l}, n_{2 l}\right)}\right)\right]^{2},
\end{aligned}
$$

where $S_{i}(i=1,2,3)$ denotes the sum of squared errors of the No. $i$ subsystem at $p$ interpolating point. as follows:

Then, according to the Method of Least Squares, formula (3.12) should be transformed

$$
\begin{aligned}
\min & S\left(\delta_{1}, \delta_{2}, \delta_{3}, \lambda_{1}, \lambda_{2}, \lambda_{3}, \sigma_{21}, \sigma_{31}, \sigma_{12}, \sigma_{32}, \sigma_{13}, \sigma_{23}, \xi_{1}, \xi_{2}, \xi_{3}\right)=\sum_{i=1}^{3} S_{i} \\
& 0<\delta_{i} \leq 1 \\
& 0<\lambda_{i} \leq 1 \\
\text { s.t. } \quad & 0<\sigma_{i d} \leq 1 \\
& 0<\xi_{i} \leq 1 \\
& i=1,2,3 \quad d=1,2,3 \quad i \neq d .
\end{aligned}
$$

By solving formula (3.13) through nonlinear optimization function fmincon of MATLAB, the synergistic coefficients of each subsystem can be figured out. 


\subsection{Solutions of Synergy Evolution Equations: Collecting, Distributing, and Transporting System of Railway Heavy Haul Transportation and Its Subsystems}

By plugging the synergistic coefficients of each subsystem into formula (2.4) and then solving it with Rugge-kutta method, the synergy evolution curves of each subsystem's ordering degree can be worked out.

By putting the results of formula (2.4) into formula (2.5), the rate of change of the synergistic degree of order can be worked out. Rugge-kutta method is applied to solve an equation whose variable is related to time, that is, the variable's derivative of time is a function of the variable and time. Since the synergy evolution equation of each subsystem is related to a function about degree of order and time, Rugge-kutta method can be applied to solve it. However, the synergy evolution equation of the collecting, distributing, and transporting system of heavy haul transportation is the rate of change of the annually synergistic degree of order, which is a concrete number, so Rugge-kutta method cannot be applied. Instead, this paper applies fourth-order Adams linear implicit formula method to work out the result. The formula is as follows:

$$
y_{j+1}=y_{j}+\frac{h}{24}\left(9 f_{j+1}+19 f_{j}-5 f_{j-1}+f_{j-2}\right) \text {. }
$$

The truncation error of the fourth-order Adams linear implicit formula is

$$
R_{n+1}=-\frac{19}{720} h^{5} y_{n}^{(5)}+O\left(h^{6}\right)
$$

where

(i) $y_{j}$ is the No. $j$ year's synergistic degree of order of the collecting, distributing, and transporting system of heavy haul transportation,

(ii) $f_{j}$ is the No. $j$ year's rate of change of the synergistic ordering degree of the collecting, distributing, and transporting system of heavy haul transportation,

(iii) $h$ is the time step, here referring to one year.

\section{Empirical Analysis}

\subsection{Overview of the Collecting, Distributing, and Transporting System of Daqin (Datong to Qin Huangdao) Railway Heavy Haul Transportation}

Daqin Railway heavy load transportation involves more than 100 coal mining enterprises, 4 nationwide big power grids, 10 big steel companies, more than 6000 industrial and mining enterprises which are coal-consuming, and 3 coal ports. From the logistics perspective, the processes of production, transportation, and marketing can be taken into a comprehensive consideration. Therefore, Daqin heavy load transportation system is consisted of three subsystems-collecting system, distributing system, and Daqin Railway. It is a large equipment-interconnected, production-linked integrated system. Its subsystems and itself have very obvious characteristics. 
By the optimization and integration of the supply of goods, most of the coal resources from the three regions of Shaanxi province, Shanxi province, and the west of Inner Mongolia are transported through Daqin Railway. The wagon flow of Daqin line consists of two parts, namely, the one from the attracting area and the one from collecting and transporting line. At the loading spot along Daqin Railway attracting area, there are 20,000-ton freight train, 10,000-ton freight train, and ordinary freight train. Achieving point-to-point scheduled transporting organization, the 20,000-ton and 10,000-ton freight trains directly run through Hudong Station, alleviating the organizing pressure of Hudong Station. Ordinary freight trains are combined into 10,000-ton freight train at technical station; 10,000-ton freight trains of Dazhun line (Datong to Zhun Ger) and Dabao line (Datong to Baotou) are organized into 20.000-ton freight train at Hudong Station.

\section{(1) The Collecting System of Daqin Railway}

The collecting system of Daqin Railway is mainly composed of 19 coal enterprises, 100 loading spots, several collecting lines such as Beitongpu line (Datong to Taiyuan), Dazhun line, Dabao line, Yungang line (Datong to the mining area of Gaoshan county), Kouquan line (Datong to the mining area of Kouquan county), and many kinds of fixed equipments and locomotive equipments.

The wagon flow north-running through Daxin Station along Beitongpu line is organized into 10,000-ton freight train at Daxin Station, and 10,000-ton freight trains organized at the loading spot go directly through Daxin Station. Along Daxin-Hanjialing line, Bazhuang Station, Huairen Station, Jinshatan Station, and Beizhuozhuang Station are capable of handling 20,000-ton freight trains, while the rest of the stations can handle 10,000ton freight trains. The wagon flow of Yungang branch, the hub of Datong, can be organized into 20,000-ton train, so is the wagon flow of Hanjialing Station. The wagon flow of Kouquan branch can be organized into 10,000-ton train. Dabao line and Dazhun line are capable of 10,000-ton freight train, which will be made into 20,000-ton freight train at Hudong Station. Wagon flows from Yangyuan Station and Zhulu Station are also 10,000-ton freight train.

\section{(2) The Distributing System of Daqin Railway}

The distributing system of Daqin Railway mainly consists of three parts, including coalconsuming companies, such as 5 nationwide power grids, 10 steel companies, more than 6000 industrial and mining enterprises, Panshan Power Plant, Zunhua Power Plant, 3 coal ports of Qinhuangdao Port, Tianjin Port, Tangshan Port and 2 distributing lines of Jigang line and Qiancao line.

The trains arriving at Niucunnan II, Caofeidian Port, and Jingtang Port are all 20,000ton freight trains. According to the request of unloading equipment, the 20,000-ton freight train can be unloaded after being divided into two 10,000-ton freight trains or be directly unloaded. The wagon flow running to Qinhuangdao Dong Station is 10,000-ton freight train. After arriving at Xizhangzhuang Station (Houying Station), it will be divided into 5,000-ton freight train. 10,000-ton freight trains running through Zuipingshan Station and Zunhuabei Station will be divided into 5,000-ton train and then sent to power plant. The 10,000-ton freight train to Tianjin Port will be divided into 5,000-ton freight train at Jixianxi Station and then sent to the port. The 10,000-ton freight trains to Jingqin line and Beijing will be divided into 5,000-ton freight train at Dashizhuang Station and Chawu Station and then go on running. 
Table 1: The previous data of the collecting, distributing, and transporting system.

\begin{tabular}{|c|c|c|c|c|c|c|c|c|c|c|c|c|}
\hline \multirow[b]{2}{*}{ 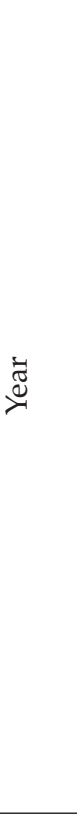 } & \multicolumn{4}{|c|}{ Collecting system } & \multicolumn{5}{|c|}{ Transporting system } & \multicolumn{3}{|c|}{ Distributing system } \\
\hline & 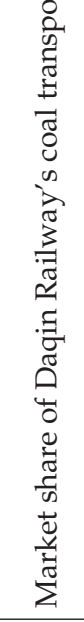 & $\begin{array}{l}\infty \\
0 \\
0 \\
0 \\
0 \\
.0 \\
\tilde{0} \\
\tilde{0} \\
1\end{array}$ & 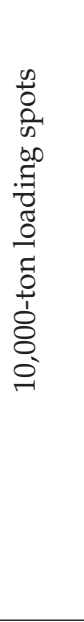 & 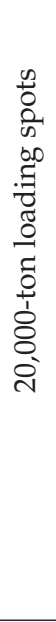 & 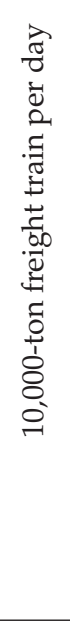 & 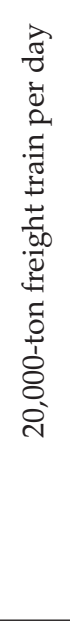 & 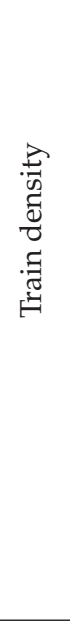 & 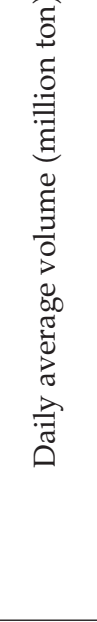 & 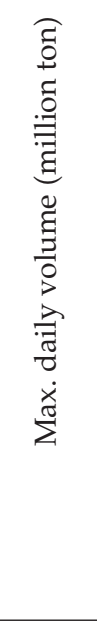 & 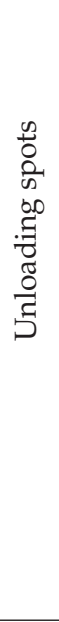 & 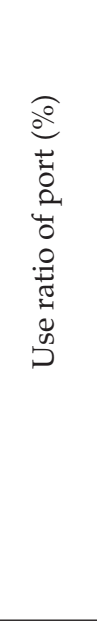 & 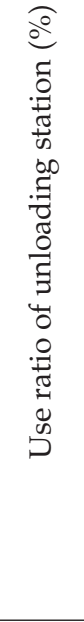 \\
\hline 2006 & 92.10 & 91 & 34 & 11 & 69.4 & 6.4 & 72 & 69.5 & 79.1 & 3 & 78.70 & 48.87 \\
\hline 2007 & 90.20 & 116 & 42 & 11 & 60.1 & 22.4 & 83.2 & 83.23 & 99.87 & 4 & 82.23 & 49.68 \\
\hline 2008 & 90.10 & 118 & 42 & 12 & 55.6 & 29.8 & 85.8 & 93.2 & 105 & 4 & 94.07 & 60.35 \\
\hline 2009 & 90.20 & 129 & 43 & 14 & 40.9 & 36.5 & 90 & 90.5 & 111.35 & 5 & 83.43 & 48.81 \\
\hline 2010 & 90.67 & 147 & 44 & 16 & 34.8 & 48.7 & 88.3 & 110.97 & 122.03 & 5 & 97.96 & 70.21 \\
\hline 2011 & 90.98 & 147 & 44 & 16 & 35.5 & 59.6 & 97 & 120.6 & 129.9 & 5 & 114.49 & 82.48 \\
\hline
\end{tabular}

\subsection{Synergy Evolutionary Analysis of the Collecting, Distributing, and Transporting System of Daqin Railway Heavy Haul Transportation}

From the beginning of 2006, the rail volume of Daqin Railway has basically kept a 50 million annual growth and reached 440 million in 2011. Therefore, this paper tries to analyze the synergy evolution process and tendency of the collecting, distributing, and transporting system of Daqin Railway heavy haul transportation by applying the data starting from 2006.

\subsubsection{Determining the Weight of Each Parameter}

This paper selects the main parameters of the three subsystems, respectively, and the parameters can be seen in Table 1. By plugging the data of each subsystem's parameters into (3.1)-(3.7), the weight of each subsystem's parameter can be worked out, as can be seen in Table 2.

\subsubsection{Determining the Degree of Order of Each Subsystem}

By plugging the data of Table 1 in (2.2), the degree of order for each subsystem can be worked out, as seen in Table 3 and Figure 1. 
Table 2: Weight of each subsystem's parameters.

\begin{tabular}{|c|c|c|c|c|c|c|c|c|c|c|c|}
\hline \multirow[b]{2}{*}{ 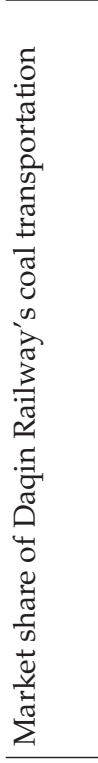 } & \multicolumn{4}{|c|}{ Collecting system } & \multicolumn{4}{|c|}{ Transporting system } & \multicolumn{3}{|c|}{ Distributing system } \\
\hline & $\begin{array}{l}0 \\
0 \\
0 \\
0 \\
0 \\
0 \\
0 \\
0 \\
0 \\
0 \\
-1\end{array}$ & 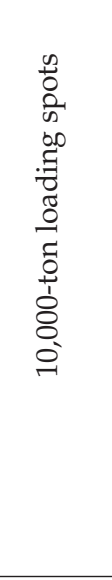 & 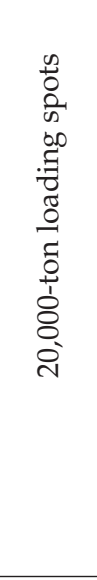 & 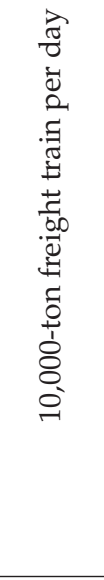 & 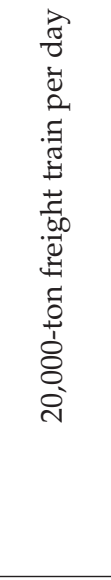 & 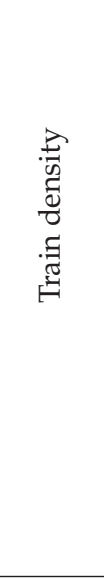 & 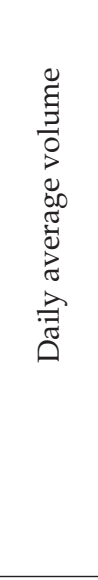 & 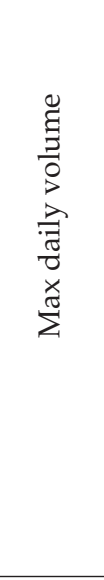 & 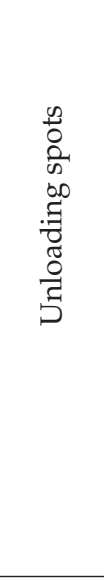 & 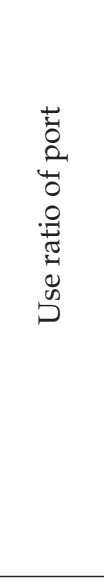 & 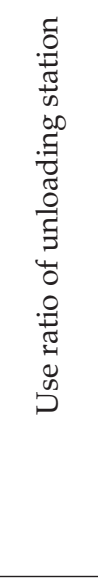 \\
\hline 0.1728 & 0.2955 & 0.3081 & 0.2236 & 0.1956 & 0.2052 & 0.1956 & 0.1984 & 0.2052 & 0.2925 & 0.3396 & 0.3679 \\
\hline
\end{tabular}

Table 3: The degree of order of each subsystem.

\begin{tabular}{lccc}
\hline Year & $\begin{array}{c}\text { Collecting } \\
\text { subsystem }\end{array}$ & $\begin{array}{c}\text { Transporting } \\
\text { subsystem }\end{array}$ & $\begin{array}{c}\text { Distributing } \\
\text { subsystem }\end{array}$ \\
\hline 2006 & 0.6127 & 0.4277 & 0.4761 \\
2007 & 0.6913 & 0.4967 & 0.5593 \\
2008 & 0.7046 & 0.5233 & 0.5987 \\
2009 & 0.7478 & 0.5186 & 0.6347 \\
2010 & 0.8019 & 0.5624 & 0.6831 \\
2011 & 0.8025 & 0.6176 & 0.7381 \\
\hline
\end{tabular}

From Table 2 and Figure 1, we can see the overall degree of order of the three subsystems presenting a rising trend. Collecting system has the highest degree of order due to its fine integration of goods, and, with the construction of strategic loading spots, its efficiency will be much higher. But influenced by Hudong Station, its degree of order in 2011 changed a little. The degree of order of the distributing system ranks the second place because of its stable flow direction of goods and its increasing distributing capability. Consequently, its degree of order presents a relatively stable increase. The degree of order of transporting system stands the last place. Though the innovation of transporting organization has improved the volume of carriage, transporting system remains as the bottleneck for the synergistic development of the collecting, distributing, and transporting system of Daqin Railway heavy haul transportation. 


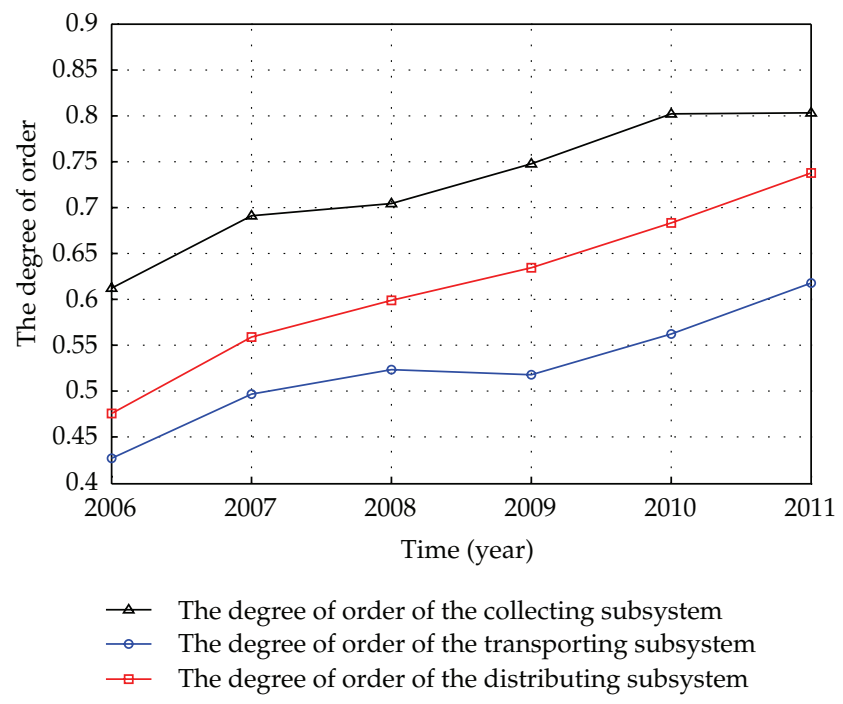

Figure 1: The change of degree of order of each subsystem.

\subsubsection{Determining the Natural Growth Rate of Each Subsystem}

By plugging the degree of order of the three subsystems into formulas (3.8)-(3.10), and applying to cubic spline interpolation and numerical differential five-point formula method, the natural growth rate of each subsystem can be figured out, respectively, as

$$
\delta_{1}=0.0548, \quad \delta_{2}=0.0746, \quad \delta_{3}=0.0892
$$

The biggest natural growth rate belongs to distributing subsystem, which means that this subsystem enjoys the fastest development when only restricted by its own environment. Transporting subsystem develops relatively slower and collecting subsystem the slowest.

\subsubsection{Solving the Self-Retardation Coefficients of all Subsystems and the Synergistic Coefficients between Them}

By plugging the already solved natural rate of growth and the degree of order into formula (3.13), the self-retardation coefficients $\lambda_{i}$ and the synergistic coefficients $\sigma_{i j}$ and $\xi_{i}$ can be worked out.

In collecting subsystem, $\lambda_{1}=0.4401, \sigma_{21}=0.0112, \sigma_{31}=0.0121$, and $\xi_{1}=0.3621$.

In transporting subsystem, $\lambda_{2}=0.6801, \sigma_{12}=0.4199, \sigma_{32}=0.0110$, and $\xi_{2}=0.0501$.

In distributing subsystem, $\lambda_{3}=0.8999, \sigma_{13}=0.5999, \sigma_{23}=0.0601$, and $\xi_{3}=0.1169$.

In terms of self-retardation coefficient we have the following.

(1) The self-retardation coefficient of distributing subsystem is the biggest, which means that its degree of order gains the best development. Under the restriction of the available resource, it will be more and more difficult for its degree of order to rise. 
(2) The self-retardation coefficient of the collecting subsystem is the smallest, which indicates that there is still room for the improvement of its degree of order. With the stable implementation of the strategic loading spots and the improvement of loading equipments, its degree of order will rise.

(3) The transporting subsystem's degree of order gains mild developmentcompared to those of the other two subsystems' and still has room to be increased.

In terms of synergistic coefficient we have the following.

(1) Due to the fact that collecting is the beginning part of the collecting, distributing, and transporting system and that its degree of order has a relatively large impact on the whole system, the collecting subsystem has the largest synergistic effect on the distributing and transporting subsystems; the synergistic degree between distributing and transporting, on the other hand, influences the degree of order of the collecting subsystem to the largest extent. For the reason that the collecting of goods and vehicles demands the cooperation between distributing and transporting so that the delivery of goods can be achieved, the synergistic degree between distributing and transporting subsystems has a relatively large impact on the collecting subsystem.

(2) Distributing subsystem has the least synergistic effect on the other two in that the unloading points and the ports of the distributing subsystem have a capacity large enough to satisfy the demand of the collecting subsystem. Therefore, the distributing subsystem has the least influence on the degree of order of the other two, while the synergistic degree between "collecting" and transporting subsystems has an intermediate effect on the degree of order of the distributing subsystem.

(3) The influence of the transporting subsystem on the other two is intermediate in that transporting connects collecting with distributing, and the self-retardation coefficient of the transporting subsystem itself is intermediate. Therefore, the transporting subsystem does not influence the other two on a large scale and the synergistic degree between the other two has the least influence on the degree of order of the transporting subsystem.

\subsubsection{The Collecting, Distributing, and Transporting System of Daqin Railway Heavy Haul Transportation and the Solution of Equation of the Synergy Evolution of the Three Subsystems}

The synergy evolution curves of the degree of order for the three subsystems can be drawn, respectively, through plugging the coefficients computed into (2.4) and solving the equation by the fourth-order Rugge-kutta method, to be seen in Figures 2, 3, and 4.

According to the synergistic theory, the cross-coupling of the input and the output, together with the nonlinear interaction among the three subsystems will drive the whole system to develop in a more organized and more efficient way until a relative stable balance is achieved, at which point the synergistic degree among the three subsystems will reach a maximum value. If there are no major events or special situations to interrupt, the stable state will last for a relatively long time until another chaos state presents itself.

From Figures 2, 3, and 4, it can be seen that the time for the three subsystems to reach a balance will be at about 2030 where the degrees of order for collecting, distributing, and 


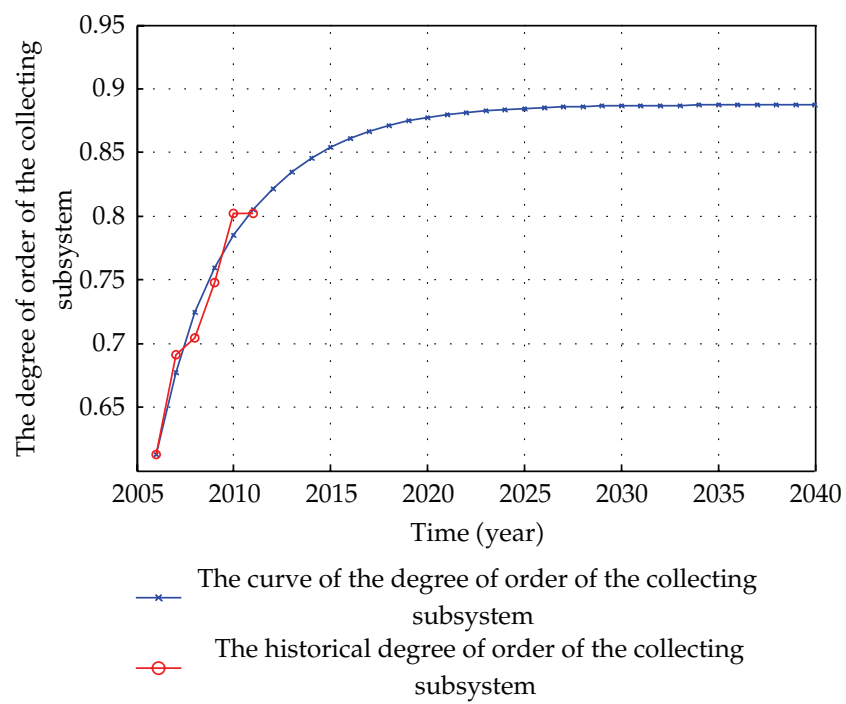

Figure 2: The synergy evolution curve of the degree of order of the collecting subsystem.

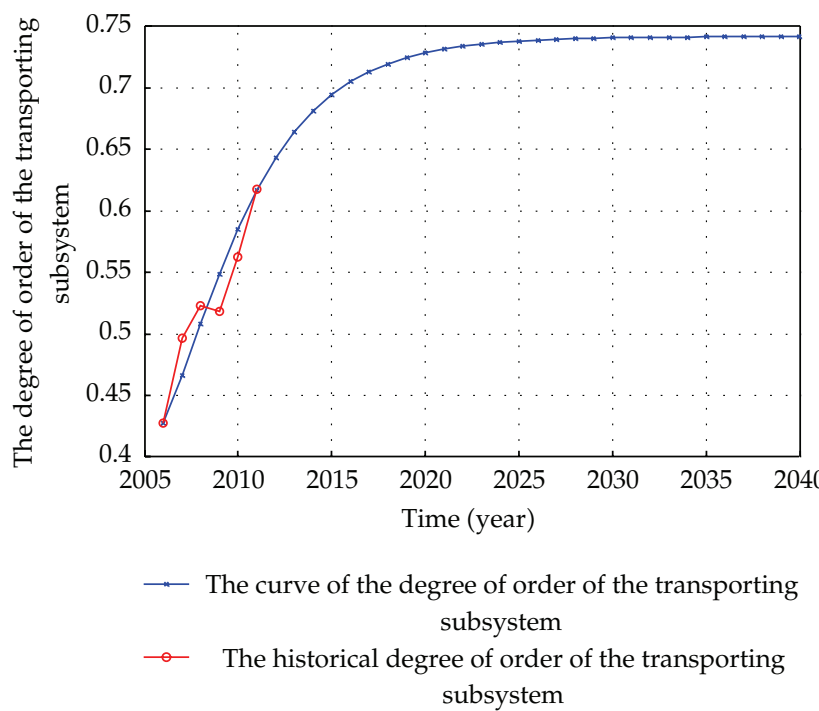

Figure 3: The synergy evolution curve of the degree of order of the transporting subsystem.

transporting will be $0.8870,0.7481$, and 0.8488 , respectively, which, considering the resources available for the three subsystems, are the values that can be achieved in the condition of the largest degree of synergy. It can be seen, through matching the degrees of order of the three subsystems in the past years with the theoretical evolution curves of the three, that the results of the modeling are, in general, in line with the reality.

With 2011 as the base year, the absolute values for the growth of degree of order of the collecting, distributing, and transporting are $0.0845,0.1305$, and 0.1107 , respectively. The rate of growth for the collecting subsystem is the smallest, for the order of degree of it is the largest among those of the three, which has reached 0.8025 in 2011. At such 


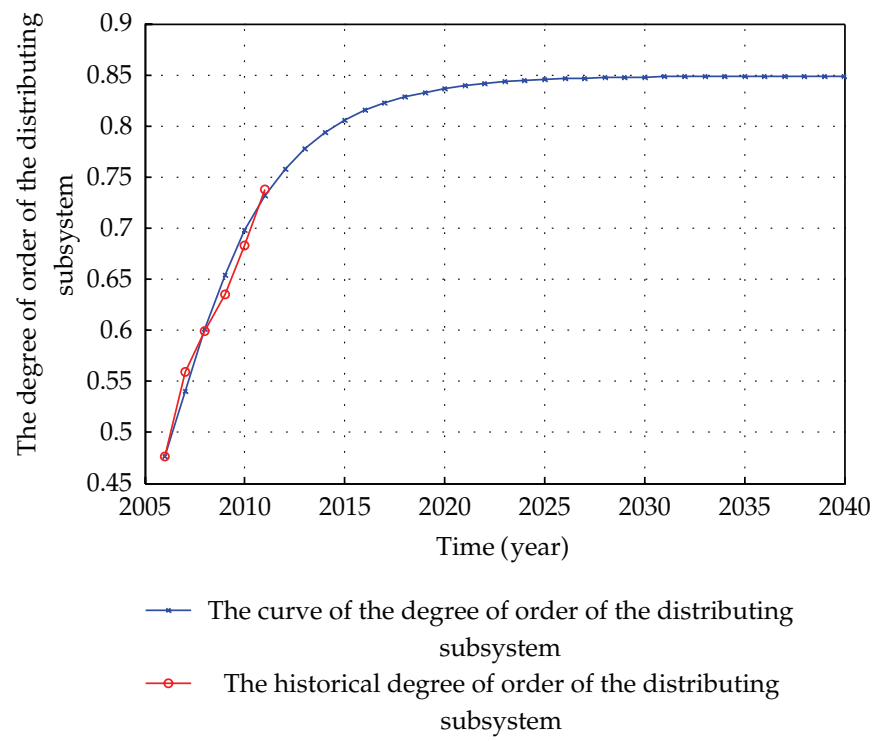

Figure 4: The synergy evolution curve of the degree of order of the distributing subsystem.

a high level, the growth of the degree of order will face much difficulty, hence a low rate of growth. The growth of the transporting subsystem is the largest due to two reasons: the degree of order of it is the smallest among the three, which restricts the synergistic development of the collecting, distributing, and transporting system of Daqin Railway heavy haul transportation, but will also increase greatly with the implementation of a series of transformation methods to expand capacity and the innovation of the transportation organizations; collecting subsystem has a large impact on the synergistic coefficient of the transporting subsystem, which means that once the order of degree of the collecting subsystem increases by 0.1 , that of the transporting subsystem will increase by 0.04199 , and, as a result of the synergistic promotion among the three, the degree of order of the transporting subsystem has the largest increase. The increase of degree of order of the distributing subsystem is intermediate but way above that of the collecting subsystem, for the former was 0.7381 in 2011 and stood at the second place among the three and still had room for growth. Besides, once the order of degree of the collecting subsystem increases by 0.1 , that of the distributing will increase by 0.5999 , and it will also increase if the synergistic order of degree of the collecting and transporting subsystems increases by 0.1. However, influenced by the self-retardation coefficient, its rate of increase is below that of the collecting subsystem.

The synergy evolution curve of the collecting, distributing, and transporting system of Daqin Railway heavy haul transportation can be drawn through plugging the degrees of order of the three subsystems calculated in (2.4) into (2.5) and solving the equation by the fourth-order Adams linear implicit formula method, to be seen in Figure 5.

It can be seen from Figure 5 that the development of the collecting, distributing, and transporting system of Daqin Railway heavy haul transportation will achieve a balance in 2030 , where the order of degree of the system will be 0.8120 , which, considering the resources and techniques available, indicates the largest degree of synergy that can be reached among the three subsystems. 


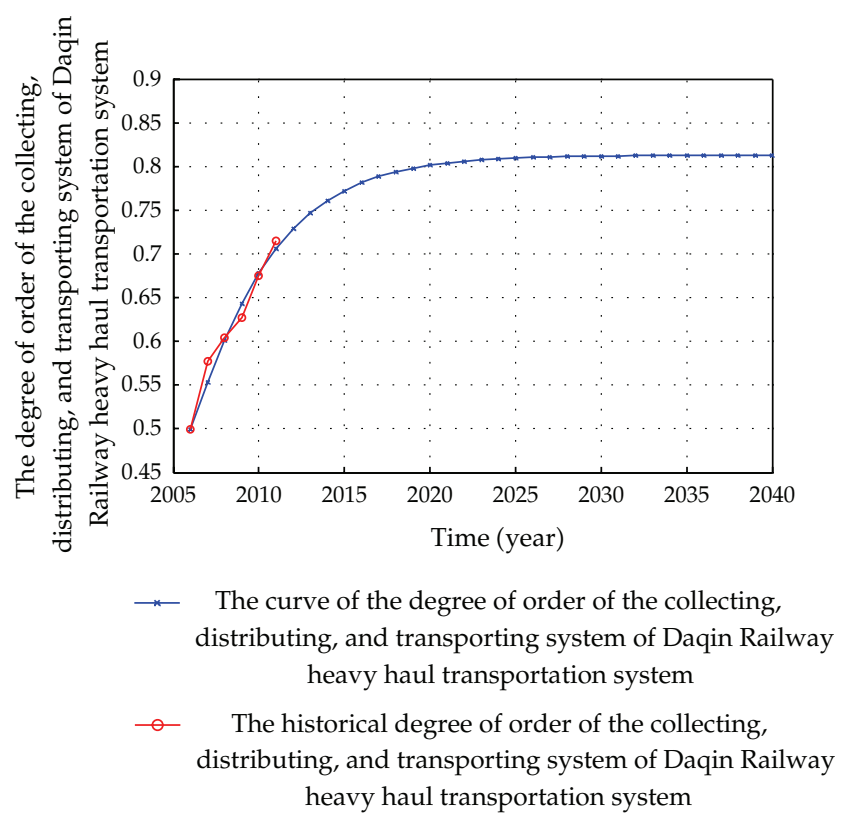

Figure 5: The synergy evolution curve of the collecting, distributing, and transporting system of Daqin Railway heavy haul transportation.

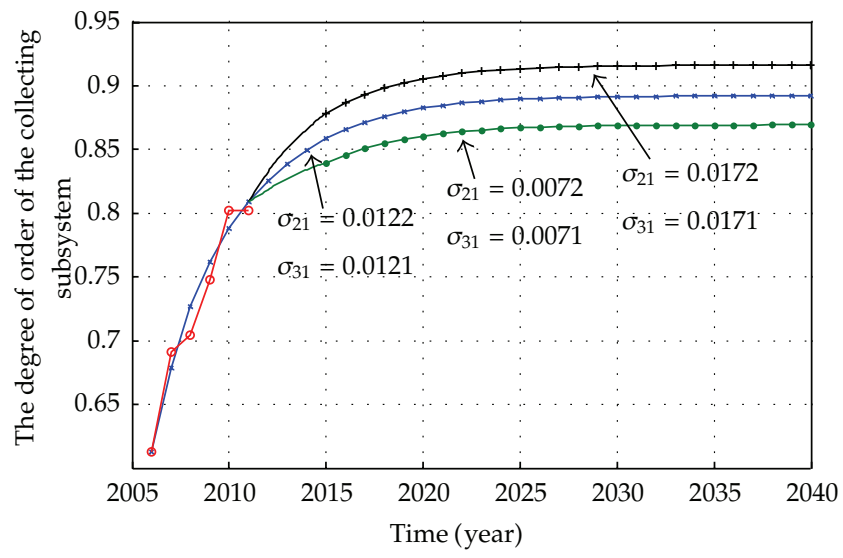

Figure 6: The ordered synergistic coevolution of the collecting subsystem with different synergistic coefficients.

\subsubsection{The Analysis of the Synergy Evolutions of the Three Subsystems and the Collecting, Distributing, and Transporting System of Daqin Railway Heavy Haul Transportation}

Based on the actual ordered synergistic coevolutions of the collecting, distributing, and transporting system of Daqin Railway heavy haul transportation and its subsystems, the ordered synergistic coevolutions of the system and its subsystems are analyzed, respectively, with a synergistic coefficient above and below the current value, to be seen in Figures 6, 7, 8, and 9. 


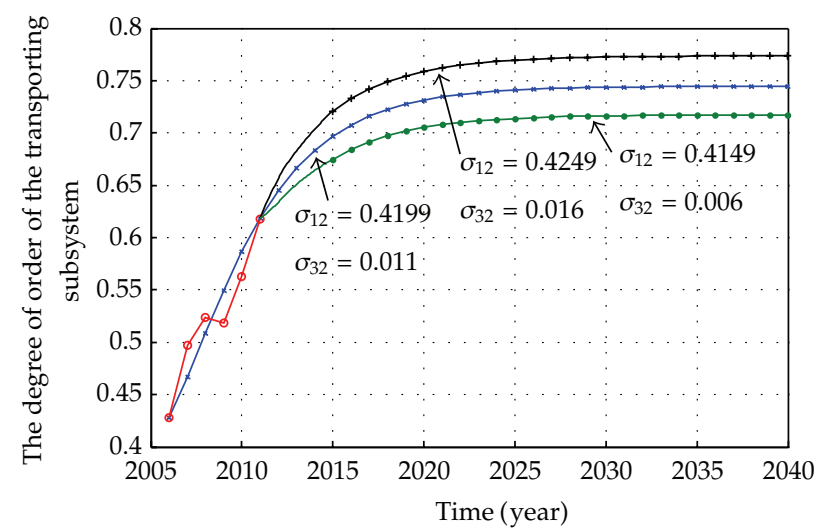

Figure 7: The ordered synergistic coevolution of the transporting subsystem with different synergistic coefficients.

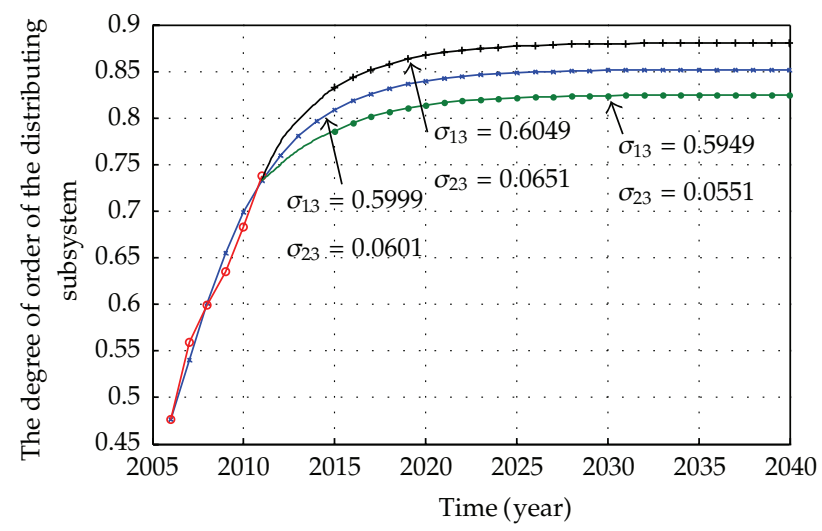

Figure 8: The ordered synergistic coevolution of the distributing subsystem with different synergistic coefficients.

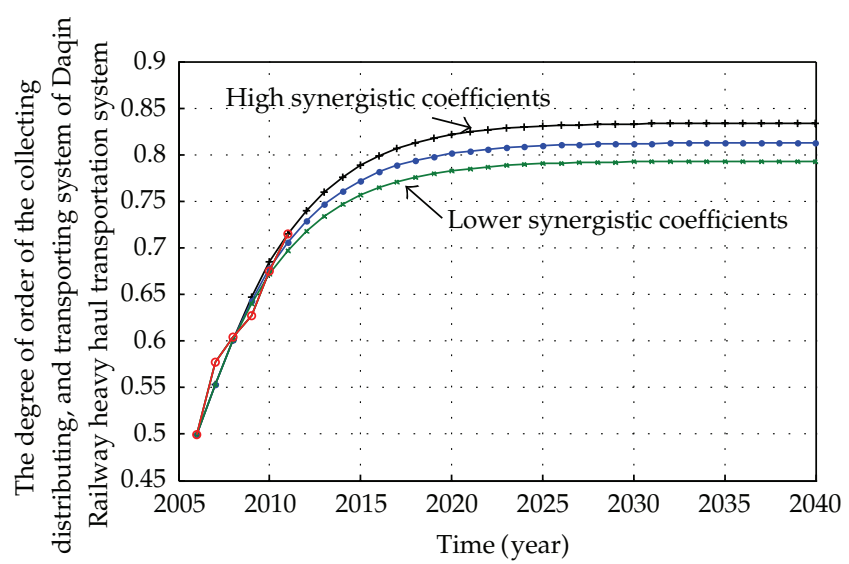

Figure 9: The ordered synergistic coevolution of the collecting, distributing, and transporting system of Daqin Railway heavy haul transportation with different synergistic coefficients. 
Figure 6 reveals the ordered synergistic coevolution of the collecting subsystem with different synergistic coefficients, which when the synergistic coefficients the other two subsystems have on it, the $\sigma_{21}$ and $\sigma_{31}$, are raised to 0.0172 and 0.0171 , respectively, it will reach a balance in about 2030 and the degree of order at balance will be raised to 0.9163 , while when the synergistic coefficients the other two subsystems have on it, the $\sigma_{21}$ and $\sigma_{31}$, are lowered to 0.0122 and 0.0121 , respectively, it will reach a balance in about 2030 and the degree of order at balance will be lowered to 0.8694 .

Figure 7 reveals the ordered synergistic coevolution of the transporting subsystem with different synergistic coefficients, which when the synergistic coefficients the other two subsystems have on it, the $\sigma_{12}$ and $\sigma_{32}$, are raised to 0.4249 and 0.0160 , respectively, it will reach a balance in about 2030 and the degree of order at balance will be raised to 0.7736, while when the synergistic coefficients the other two subsystems have on it, the $\sigma_{12}$ and $\sigma_{32}$, are lowered to 0.4149 and 0.0060 , respectively, it will reach a balance in about 2030 and the degree of order at balance will be lowered to 0.7172 .

Figure 8 reveals the ordered synergistic coevolution of the distributing subsystem with different synergistic coefficients, which when the synergistic coefficients the other two subsystems have on it, the $\sigma_{13}$ and $\sigma_{23}$, are raised to 0.6049 and 0.0651 , respectively, it will reach a balance in about 2030 and the degree of order at balance will be raised to 0.8860 , while when the synergistic coefficients the other two subsystems have on it, the $\sigma_{13}$ and $\sigma_{23}$, are lowered to 0.5949 and 0.0551 , respectively, it will reach a balance in about 2030 and the degree of order at balance will be lowered to 0.8249 .

Figure 9 reveals the ordered synergistic coevolution of the collecting, distributing, and transporting system of Daqin Railway heavy haul transportation with different synergistic coefficients, which when the ordered synergistic degree among the three subsystems is raised, it will reach a balance in about 2030 and the degree of order at balance will be raised to 0.8350 , while when the ordered synergistic degree among the three subsystems is lowered, it will reach a balance in about 2030 and the degree of order at balance will be lowered to 0.7899 .

It can be concluded from the above analyses that the ordered synergy within and among the three subsystems contributes to the uprising of the degree of order of the whole system and benefits the more organized and more efficient development of the collecting, distributing, and transporting system of Daqin Railway heavy haul transportation. Since the collecting, distributing, and transporting system of Daqin heavy haul transportation has only existed for a relatively short time, the parameter data may fluctuate.

\section{Conclusion}

(1) The paper builds a synergistic evolution model for the collecting, distributing, and transporting system of railway heavy haul transportation through the adoption of the concepts relevant to the degree of synergy of complex system and the application of the coevolution theory. The model is then transformed by spline interpolation method and fivepoint numerical differentiation formula into a least squares problem with linear constraint conditions, which is solved by the use of fourth-order Rugge-kutta method and fourth-order Adams linear implicit formula method.

(2) The degrees of order of the collecting, distributing, and transporting system of railway heavy haul transportation and its three subsystems increase when the synergistic coefficient among the three subsystems increases and decrease when the latter decreases. 
(3) The model used in the empirical analysis of the Daqin Railway can preferably analyze the ordered synergistic evolution of the collecting, distributing and transporting system of Daqin Railway heavy haul transportation. The collecting, distributing, and transporting system of Daqin Railway heavy haul transportation and the collecting, distributing, and transporting subsystems will reach a balance about 2030, where the order of degree of the system and the three subsystems will be $0.8120,0.8879,0.7481$, and 0.8488 , respectively, which, considering the resources available at present, are the values that can be achieved under the condition of the largest degree of synergy. Therefore, the model is proved to be reasonable and feasible.

\section{Acknowledgment}

This work was supported by the Fundamental Research Funds for the Central Universities (Grant no. 2010QZZD021).

\section{References}

[1] W. Hook and M. Replogle, "Motorization and non-motorized transport in Asia: transport system evolution in China, Japan and Indonesia," Land Use Policy, vol. 13, no. 1, pp. 69-84, 1996.

[2] J. L. Adler, G. Satapathy, V. Manikonda, B. Bowles, and V. J. Blue, "A multi-agent approach to cooperative traffic management and route guidance," Transportation Research Part B, vol. 39, no. 4, pp. 297-318, 2005.

[3] J. Hackney and F. Marchal, "A coupled multi-agent microsimulation of social interactions and transportation behavior," Transportation Research Part A, vol. 45, no. 4, pp. 296-309, 2011.

[4] S. J. Jeong, C. G. Lee, and J. H. Bookbinder, "The European freight railway system as a hub-and-spoke network," Transportation Research Part A, vol. 41, no. 6, pp. 523-536, 2007.

[5] J. W. Konings, "Integrated centres for the transshipment, storage, collection and distribution of goods: a survey of the possibilities for a high-quality intermodal transport concept," Transport Policy, vol. 3, no. 1-2, pp. 3-11, 1996.

[6] F. Fenling and L. Dan, "Heavy-haul train's operating ratio, speed and intensity relationship for Daqin railway based on cellular automata model," Information Technology Journal, vol. 11, no. 1, pp. 126-133, 2012.

[7] F. Fenling and L. Feiran, "Railway heavy-haul cargo distribution and transportation system incentive mechanism based on principal-agent theory," Information Technology Journal, vol. 11, no. 7, pp. 884$890,2012$.

[8] Z. Jun, D. Wen, and Z. Yue, "Integrated evaluation for synergetic development of city traffic system based on DEA model," Computer Engineering and Applications, vol. 43, no. 32, pp. 245-248, 2007.

[9] Z. Yan and Z. Bei-Hua, "Evaluative equation for container multi-modal transport system," Navigation of China, no. 4, pp. 92-104, 2006.

[10] T. Huaihai, "High-speed railway passenger hub for collection and distribution system structure coupling," Southeast University, Nanjing, China, 2009.

[11] R. B. Norgaard, "Environmental economics: an evolutionary critique and a plea for pluralism," Journal of Environmental Economics and Management, vol. 12, no. 4, pp. 382-394, 1985.

[12] R. Costanza, L. Wainger, and C. Folke, "Modeling complex ecological economic systems," Bio Science, vol. 43 , no. 8 , pp. $545-556,1993$.

[13] C. S. Holling, "Understanding the complexity of economic, ecological, and social systems," Ecosystems, vol. 4, no. 5, pp. 390-405, 2001.

[14] L. Aihua, L. Yuanyuan, and L. Jianqiang, "Preliminary discussion on synergetic development between water resources and social economy and eco- environment," Yangtze River, vol. 42, no. 18, pp. 117-121, 2011.

[15] W. Yuming and Z. Yan, "Coupled coordinated development of regional economic growth and environmental research," Resources Science, vol. 30, no. 1, pp. 25-30, 2008. 
[16] F. Shangyou, L. Guoquan, and M. Yadong, "Water resources ecological and economic system and its sustainable development," Engineering Journal of Wuhan University, vol. 28, no. 6, pp. 624-629, 1995.

[17] M. Xiangdong, S. Jinhua, and H. Zhenyun, "Co-evolutionary study on the ecological environment and the social economy multiplexed system," Advances in Water Science, vol. 20, no. 4, pp. 566-571, 2009.

[18] M. Qingsong and H. Wenxiu, "Study of the coordinating measurement model with respect to composite system," Journal of Tianjing University, vol. 33, no. 4, pp. 444-446, 2000.

[19] P. Bak and K. Chen, "Self-organized criticality," Scientific American, vol. 264, no. 1, pp. 26-33, 1991.

[20] M. Bobrek and M. Sokovic, "Integration concept and synergetic effect in modern management," Journal of Materials Processing Technology, vol. 175, no. 1-3, pp. 33-39, 2006. 


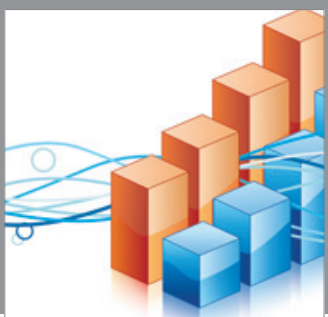

Advances in

Operations Research

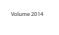

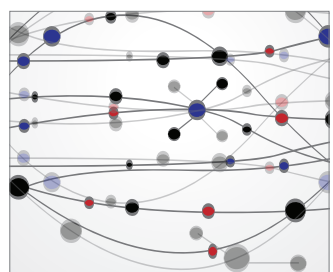

\section{The Scientific} World Journal
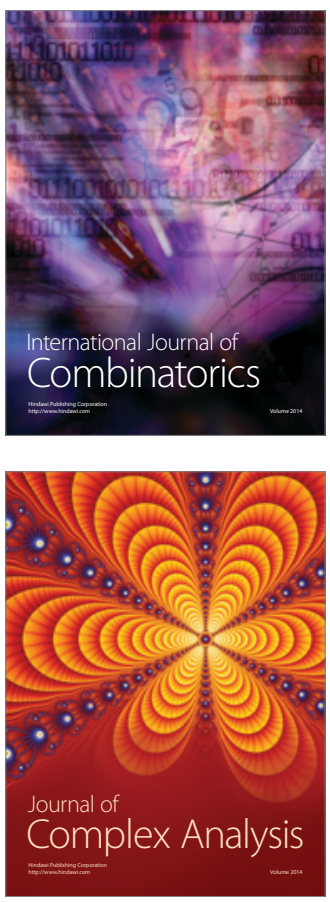

International Journal of

Mathematics and

Mathematical

Sciences
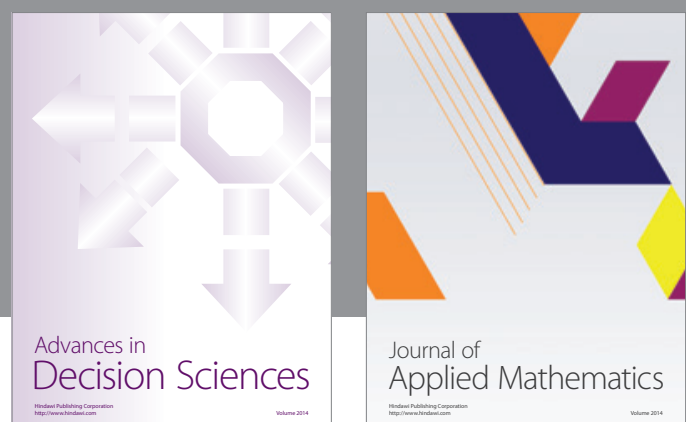

Journal of

Applied Mathematics
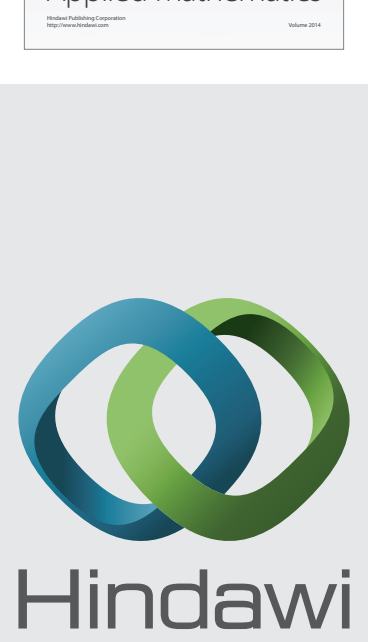

Submit your manuscripts at http://www.hindawi.com
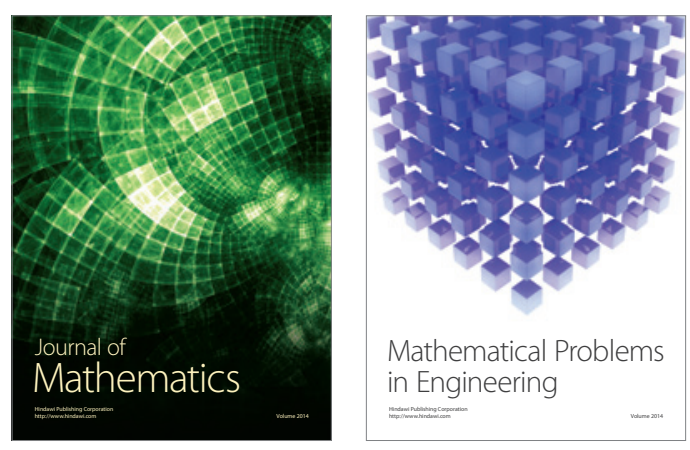

Mathematical Problems in Engineering
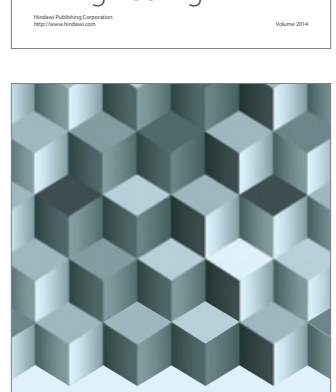

Journal of

Function Spaces
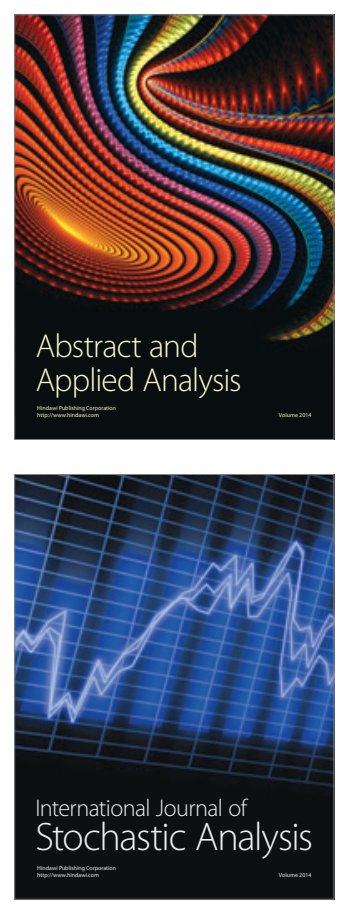

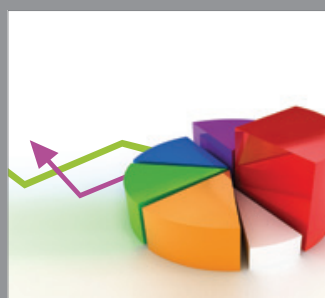

ournal of

Probability and Statistics

Promensencen
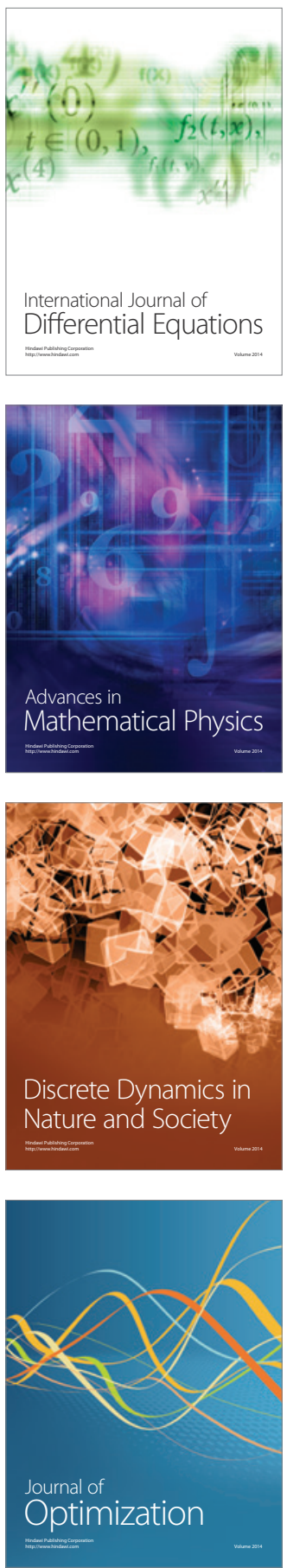